\title{
Inter-relation between "classic" motor neuron disease and frontotemporal dementia: neuropsychological and single photon emission computed tomography study
}

\author{
Paul R Talbot, Peter J Goulding, James J Lloyd, Julie S Snowden, David Neary, \\ Humberto J Testa
}

Department of Nuclear Medicine, Manchester Royal Infirmary, Manchester, UK H J Testa

Correspondence to Dr P R Talbot, Cerebra Function Unit, Department of Neurology, Manchester Royal Infirmary, Oxford Road, Mancheste M13 9WL, UK

Received 17 October 1994 and in revised form 10 January 1995. Accepted 12 January 1995

\section{$(F$ Neurol Neurosurg Psychiatry 1995;58:541-547)}

Keywords: motor neuron disease; frontotemporal dementia; single photon emission computed tomography.

Motor neuron disease (MND) is a degenerative disorder of unknown aetiology that manifests progressive weakness of bulbar, limb, thoracic, and abdominal musculature. ${ }^{1}$ The term "classic" motor neuron disease (cMND) refers to a clinical syndrome in which signs are restricted to those of upper and lower motor neuron involvement. Traditionally,

\begin{abstract}
Department of Neurology P R Talbot P J Goulding J S Snowden D Neary

Department of Medical Physics J J Lloyd

Abstract

The purpose of this study was to examine the possible association between "classic" motor neuron disease (cMND) and frontotemporal dementia (FTD), using neuropsychological evaluation and single photon emission computed tomography (SPECT). Psychological tests assessing language, perceptuospatial, memory, and "frontal lobe" functions were given to patients with CMND and test scores were compared with those of normal control subjects. ${ }^{99 m}$ Tc-HMPAO SPECT was performed on patients with cMND, FTD and motor neuron disease (FTD/MND), FTD alone, and normal control subjects. Regional cerebral blood flow indices $(\mathbf{r C B F})_{i}$ were determined in 36 cortical regions, and differences between grouped rCBF $_{i}$ data were investigated by canonical discriminant analysis.

There were significant group differences in the scores of picture sequencing and token tests in patients with cMND compared with normal controls. Regional $\mathrm{CBF}_{\mathrm{i}}$ data showed frontal and anterior temporal reductions in patients with cMND compared with normal controls. A similar pattern of SPECT abnormality was seen in patients with FTD/MND and FTD alone, but to a more pronounced degree than in patients with cMND.

Neuropsychological and SPECT findings in cMND, FTD/MND, and FTD showed a common pattern of cerebral involvement, most pronounced in the second two conditions. It is suggested that $c M N D$, FTD/MND, and FTD represent a clinical range of a pathological continuum.
\end{abstract}

patients with cMND have been considered to be free from cognitive impairment. ${ }^{2}$ Evidence is emerging, however, to suggest that cognitive impairment may occur, albeit of mild degree, implicating more widespread cerebral abnormality extending beyond motor cortices and corticospinal tracts. Some authors ${ }^{3}$ have shown generalised impairment, whereas others $^{4-7}$ have provided evidence of frontal lobe dysfunction. The presence of cognitive impairment in cMND has not though, invariably been detected. ${ }^{8}{ }^{9}$ Structural MRI in cMND has typically shown cerebral abnormality restricted to the corticospinal tracts ${ }^{9-11}$ and motor cortices. ${ }^{12}$ Positron emission tomography and single photon emission computed tomography (SPECT), which are more sensitive than MRI in delineating the extent of functional abnormality within the brain, ${ }^{13-15}$ have shown abnormality outside the motor cortices, although findings are not entirely uniform. Some studies have shown generalised abnormality, ${ }^{561617}$ whereas others have found cortical changes restricted to the prefrontal gyri $^{18}$ and medial frontal regions. ${ }^{7}$ In further studies of cMND, no impairment of cerebral metabolism has been shown. ${ }^{919}$

It is increasingly recognised that nonGuamanian forms of MND may be associated with dementia, although it is uncertain whether this dementing condition should be considered a clinical variant of $\mathrm{MND}^{2}{ }^{20}$ or a separate disease entity. ${ }^{21} \mathrm{MND}$ usually follows, but may accompany or occasionally precede the onset of dementia. ${ }^{21}$ Cognitive impairment manifests as a profound breakdown in personality and social conduct together with a dynamic spontaneous speech, culminating in mutism. ${ }^{2021}$ The nature of psychological breakdown is identical to that encountered in FTD, ${ }^{22}$ implicating frontal lobe involvement. MRI $^{21}$ and SPECT 9182023 findings in patients with FTD and MND (FTD/MND) have supported this assumption, and have shown frontal and anterior temporal cerebral abnormality. Furthermore, pathological studies of $\mathrm{FTD} / \mathrm{MND}^{24}$ and FTD $^{24} 25$ have shown an identical form of non-Alzheimer cerebral atrophy in a predominantly frontal and anterior temporal distribution.

The existence of FTD/MND raises the possibility of a link between cMND and 
FTD. The purpose of this study was to consider the possible association between these conditions, by prospective evaluation of cognitive abilities in cMND and by comparing the pattern of SPECT abnormality in cMND with that encountered in FTD/MND and FTD alone.

\section{Subjects and methods \\ STUDY GROUP}

The study group consisted of 19 consecutive referrals to the Department of Neurology who fulfilled clinical criteria for probable MND. ${ }^{26}$ The diagnosis was supported by EMG findings of chronic partial denervation in more than one limb and normal nerve conduction. Four patients had initial bulbar involvement. None were terminally ill or had clinical evidence of respiratory failure. All patients were able to take part in neuropsychological evaluation without becoming unduly fatigued, and none of the patients had depressive symptoms. In none of the study group was cognitive impairment clinically evident. Indeed, patients were assessed by two fully trained neurologists and all were recruited to a drug trial for $\mathrm{MND}$, in which clinical evidence of cognitive impairment was an exclusion criterion. (Scientific Pan-European Collaboration in Amyotrophic Lateral Sclerosis (SPECIALS); a multinational randomised placebo controlled parallel groups trial of branched chain amino acids in amyotrophic lateral sclerosis.)

\section{REFERENCE GROUPS}

Eight patients fulfilled clinical criteria for FTD/MND, ${ }^{25}$ five of whom were the subject of an earlier report. ${ }^{20}$ In all patients, cognitive impairment implicating frontal lobe dysfunction was the presenting symptom, followed after several months by the clinical onset of MND. Six patients had an initial bulbar manifestation of MND. The diagnosis of MND was supported by EMG findings and normal nerve conduction. Pathological confirmation of diagnosis has since been obtained in six patients at necropsy..$^{24}$

Twenty nine patients fulfilled clinical criteria for FTD. ${ }^{25}$ All patients presented with a profound alteration in personality and social conduct, implicating frontal lobe involvement. There was no clinical suspicion of MND in any of the patients and therefore EMG studies were not performed. Computed tomography showed generalised cerebral atrophy and EEG recordings were normal.

Table 1 Study and reference group characteristics

\begin{tabular}{|c|c|c|c|c|c|}
\hline & No & $\begin{array}{l}\text { Sex } \\
(M: F)\end{array}$ & $\begin{array}{l}\text { Age }(y) \\
(\text { mean }(S D))\end{array}$ & $\begin{array}{l}\text { Duration of history } \\
\text { (mean }(S D)) \\
\text { (months) }\end{array}$ & $\begin{array}{l}\text { MND } \\
\text { characteristics } \\
(B: L)\end{array}$ \\
\hline $\begin{array}{l}\text { cMND } \\
\text { Controls } \\
\text { FTD/MND } \\
\text { FTD }\end{array}$ & $\begin{array}{r}19 \\
10 \\
8 \\
29\end{array}$ & $\begin{array}{c}10: 9 \\
4: 6 \\
8: 0 \\
15: 14\end{array}$ & $\begin{array}{l}58.4(12.3) \\
54.9(15 \cdot 8) \\
61 \cdot 1(10 \cdot 9) \\
57.6(10 \cdot 9)\end{array}$ & $\begin{array}{l}19 \cdot 6(6 \cdot 8) \\
\\
20 \cdot 6(4 \cdot 7) \\
35 \cdot 6(18 \cdot 8)\end{array}$ & $\begin{array}{l}4: 15 \\
6: 2\end{array}$ \\
\hline
\end{tabular}

$\mathrm{B}=$ initial bulbar involvement; $\mathrm{L}=$ initial limb involvement.
Patients were qualitatively similar to a group of 12 patients in whom pathological confirmation of diagnosis has been obtained at necropsy. ${ }^{24}$

Ten normal subjects, who were spouses of patients with cMND, served as controls. Table 1 shows the age, sex, and clinical characteristics of the study and reference groups. One way analysis of variance (ANOVA) showed no significant differences between groups for age $(P=0.30)$.

Informed consent was obtained from patients with cMND and normal control subjects, and approval was granted by the local ethics committee and the administration of radioactive substances advisory committee.

\section{NEUROPSYCHOLOGICAL EVALUATION}

To determine the nature of cognitive impairment in cMND, a range of psychological tests were given assessing language, perceptuospatial, memory, and "frontal lobe" functions. The frontal lobe tests used had previously been shown to yield particularly impaired performance in both patients with FTD/MND and FTD alone. ${ }^{20} 22$ Neuropsychological test scores in the cMND group were compared with those of normal controls.

Language performance was measured by the Boston naming test ${ }^{27}$ and token test, ${ }^{28}$ and visuospatial skills by dot counting, position discrimination, number location, and cube analysis subtests from the visual object and space perception (VOSP) battery. ${ }^{29}$ Verbal and non-verbal memory were assessed with the recognition memory test for words and faces. ${ }^{30}$ Each of these tests was scored according to the total number of correct responses.

Frontal lobe function was assessed by the modified version of the Wisconsin card sort test (NCST), ${ }^{31}$ a picture sequencing task, ${ }^{32}$ and a verbal fluency task, ${ }^{33}$ all of which yield highly impaired performance in patients with FTD/MND ${ }^{20}$ and FTD. ${ }^{22}$ The NCST was scored according to the number of categories, errors, and perseverative errors in accordance with Nelson, ${ }^{31}$ except that testing continued until all cards had been placed, giving a maximum total of eight rather than six categories. Picture sequencing was scored according to the total number of sequencing errors. Verbal fluency was scored according to the total number of different words (beginning with the letters $\mathrm{F}, \mathrm{A}$, and $\mathrm{S}$ ) generated in three consecutive one minute periods.

The national adult reading test (NART) ${ }^{34}$ was used to provide a measure of premorbid ability, on the basis of which patients with cMND and normal controls could be matched. This test was scored according to the total number of correct responses.

\section{SINGLE PHOTON EMISSION COMPUTED} TOMOGRAPHY ANALYSIS

All study patients and reference group subjects were injected with $500 \mathrm{MBq}$ of 99m Tc-hexamethylpropylene amine oxime (HMPAO) while seated in quiet and relaxed surroundings with eyes open. Patient data were acquired and reconstructed with a 
Table 2 Psychological test group scores for $c M N D$ study group and normal controls

\begin{tabular}{|c|c|c|c|c|}
\hline & \multirow{2}{*}{$\begin{array}{l}\text { Score } \\
\text { range }\end{array}$} & \multicolumn{2}{|c|}{ Median $(I Q R)$ test scores } & \multirow{2}{*}{$\begin{array}{l}M W \text { test } \\
P \text { values }\end{array}$} \\
\hline & & Controls & $c M N D$ & \\
\hline NART & $0-50$ & $32(17 \cdot 5)$ & $26(24 \cdot 0)$ & 0.56 \\
\hline Token test & $0-36$ & $36(0.3)$ & $35(3.0)$ & $0.03^{\star}$ \\
\hline Boston naming & $0-60$ & $53(8 \cdot 3)$ & $52(5 \cdot 0)$ & 0.93 \\
\hline VOSP: dot counting & $0-10$ & $10(0 \cdot 25)$ & $10(0.0)$ & 0.81 \\
\hline position disc & $0-20$ & $20(1 \cdot 0)$ & $20(0.0)$ & 0.81 \\
\hline no location & $0-10$ & $9(3.0)$ & $9(2.0)$ & 0.89 \\
\hline cube analysis & $0-10$ & $10(0 \cdot 25)$ & $10(1 \cdot 0)$ & 0.41 \\
\hline RMT: words & $0-50$ & $47(4 \cdot 8)$ & $47(9 \cdot 5)$ & 0.58 \\
\hline faces & $0-50$ & $42(3.8)$ & $38(8 \cdot 0)$ & $0 \cdot 13$ \\
\hline Verbal fluency task & & $48(16 \cdot 5)$ & $38(18 \cdot 0)$ & 0.47 \\
\hline NCST: categories & & $7(2 \cdot 1)$ & $5(4 \cdot 0)$ & 0.056 \\
\hline errors & & $7(12 \cdot 0)$ & $11(21 \cdot 5)$ & $0 \cdot 11$ \\
\hline perseverative errors & & $3(3 \cdot 8)$ & $4(5 \cdot 0)$ & $0 \cdot 30$ \\
\hline Picture sequencing task (errors) & & $1(1 \cdot 3)$ & $3(5 \cdot 0)$ & $0.02^{\star}$ \\
\hline
\end{tabular}

$\star P<0.05$.

All scores refer to the total number of correct responses except where stated.

$\mathrm{IQR}=$ inter-quartile range; $\mathrm{MW}$ test = Mann-Whitney $U$ test (with correction for ties);

NART = national adult reading test; VOSP = visual object and space perception test; RMT = recognition memory test; NCST $=$ revised Wisconsin card sort test.
Toshiba GCA-901A/SA integrated digital gamma camera and computer system utilising a single rotating detector fitted with a low energy high resolution collimator. The method of SPECT reconstruction and analysis was identical to that in a previous study, ${ }^{35}$ and is described briefly.

Data from SPECT were reformatted to provide 2 pixel $(8 \mathrm{~mm}$ ) thick transaxial sections parallel to the orbitomeatal line. Three transaxial sections were selected according to the following criteria. The lowest section displayed subcortical grey matter, orbitofrontal, and temporal cortices. The middle section was above subcortical grey matter and displayed frontal, parietal, and occipital cortices. The highest section was above the corpus callosum and displayed the frontal and parietal
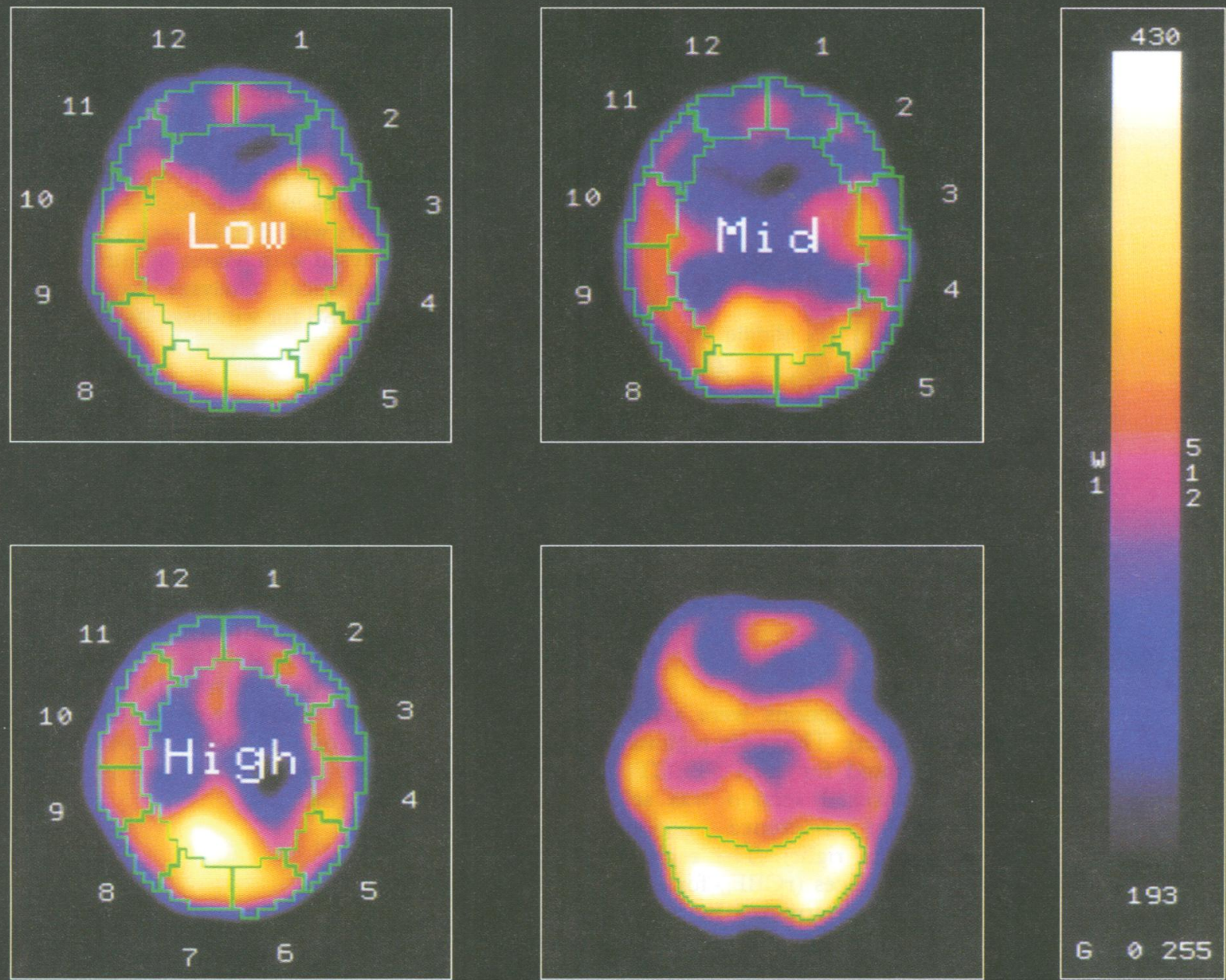

Figure 1 Transaxial sections and regions used to provide $r C B F_{i}$ data in a patient with frontotemporal dementia.

Top left: regions of interest in low section. $1=$ left anterior orbitofrontal; $2=$ left middle orbitofrontal; $3=$ left anterior temporal; $4=$ left posterior temporal; $5=$ left posterior parietal; $6=$ left posterior parietal and occipital; $7=$ right posterior parietal and occipital; $8=$ right posterior parietal; $9=$ right posterior temporal; $10=$ right anterior temporal; $11=$ right middle orbitofrontal; $12=$ right anterior orbitofrontal. Top right: regions of interest in middle section. $1=$ left anterior frontal; $2=$ left middle frontal; $3=$ left posterior frontal; 4 = left anterior parietal; 5 = left posterior parietal; $6=$ left posterior parietal and occipital; $7=$ right posterior parietal and occipital; $8=$ right posterior parietal; $9=$ right anterior parietal; $10=$ right posterior frontal; 11 = right middle frontal; 12 = right anterior frontal. Bottom left: regions of interest in high section. $1=$ left anterior frontal; $2=$ left middle frontal; $3=$ left posterior frontal; $4=$ left anterior parietal; 5 and $6=$ left posterior parietal; 7 and $8=$ right posterior parietal; $9=$ right anterior parietal; $10=$ right posterior frontal; $11=$ right middle frontal; $12=$ right anterior frontal. Bottom right: cerebellar reference region section. 
Normal controls
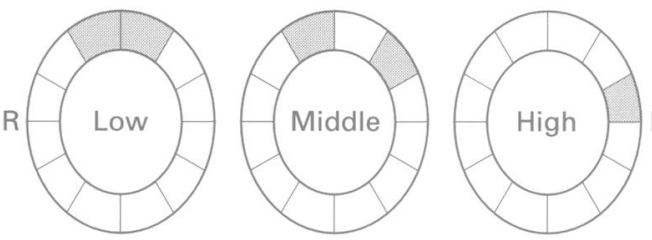

cMND
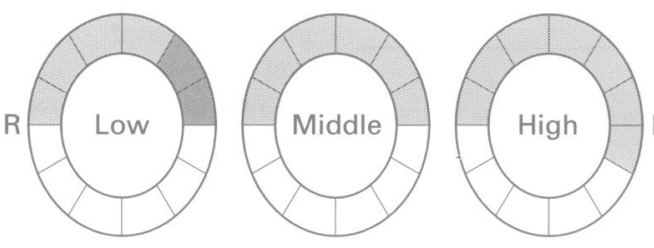

FTD/MND
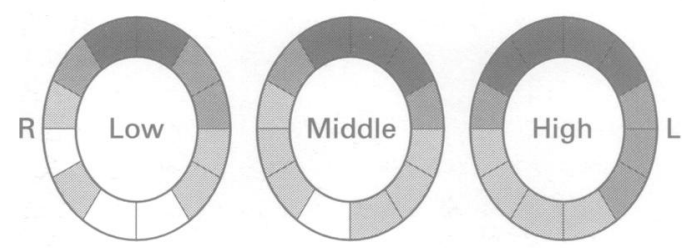

FTD

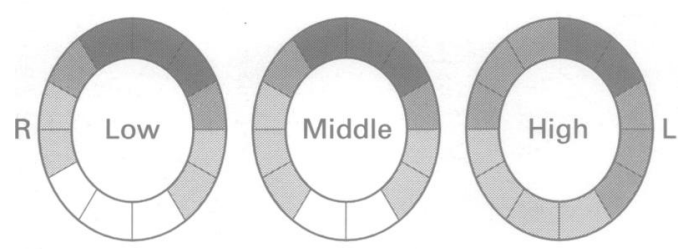

Mean $\mathrm{rCBF}_{\mathrm{i}}(\%)$

$\geq 80 \square 75-79.9 \square 70-74.9$

Figure 2 Schematic representation of grouped mean regional cerebral blood flow indices $\left(r C B F_{i}\right)$ data.

cortices. The sections were separated by 4 pixels $(16 \mathrm{~mm})$. Thirty six regions of interest were generated for each SPECT (fig 1). A further transaxial section was selected and a cerebellar reference region defined (fig 1 bottom right). The regional cerebral blood flow indices $\left(\mathrm{rCBF}_{\mathrm{i}}\right)$ for each region of interest were determined by normalising the count densities to the cerebellar reference region. The spatial resolution of the system within transaxial sections was 4 pixels (16 $\mathrm{mm}$ ), and the interplanar resolution was 2.5 pixels $(10 \mathrm{~mm})$.

This method of measurement ensured reproducibility of data acquisition, reconstruction, and analysis. ${ }^{35}$ The cerebellum was used as the reference region because it has been shown to be the most appropriate reference region in the quantification of SPECT in FTD. ${ }^{35}$ Although use of the cerebellum in
MND might be considered inappropriate due to the close proximity of brain stem pathology, previous PET studies of MND have shown the cerebellum to be spared. ${ }^{51617}$

DATA ANALYSIS AND STATISTICS

To summarise the $\mathrm{rCBF}_{\mathrm{i}}$ data within the study and reference groups, the mean values for each region of interest were calculated. The differences between groups were investigated with canonical discriminant analysis. This analysis finds those linear combinations of the original $\mathrm{rCBF}_{\mathrm{i}}$ data that maximise the ratio of between group to within group differences. Each linear combination (weighted sum) represents a discriminant function (DF). In this case three DFs were produced, which accounted for all the variation in the data between the four groups; the first DF accounted for $47.7 \%$ of the total variation, the second $28.2 \%$, and the third $24.1 \%$. These functions were evaluated for each patient and control subject and the value of the DFs for each individual referred to as DF scores. Differences between group mean $\mathrm{DF}$ scores were investigated with one way analysis of variance (ANOVA) and post hoc pair-wise comparisons with $t$ tests (with Duncan correction for multiple comparisons). To aid interpretation of the DFs the correlation between the original $\mathrm{rCBF}_{\mathrm{i}}$ variables and DFs were calculated.

Differences in psychological test results for the patients with cMND and normal controls were analysed with Mann-Whitney $U$ tests.

All statistical analyses were performed with the SPSS for windows statistical package (version 6.0).

\section{Results}

Table 2 shows the psychological test median scores for patients with cMND and normal control subjects. Performance was similar between the two groups for language, and perceptuospatial and memory tasks, with the exception of the token test, which elicited ceiling level performance in normal control subjects and occasional errors in patients with cMND. For tests of frontal lobe dysfunction, scores were worse for patients with cMND, although group differences reached statistical significance only in the case of the picture sequencing task.
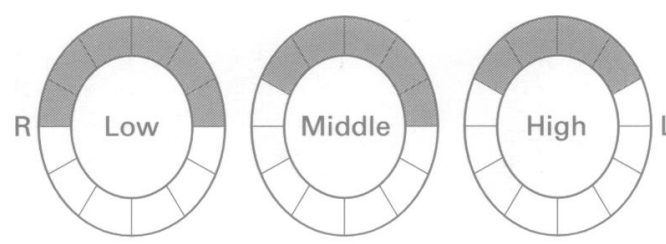

Correlation coefficient between first DF and original $\mathrm{rCBF}_{\mathrm{i}}$ : $\square<0.25 \square 0.25-0.50$

Figure 3 Schematic representation of first discriminant function (DF). 
Figure 4 Mean (2SD) discriminant function $(D F)$ scores for study and reference groups.

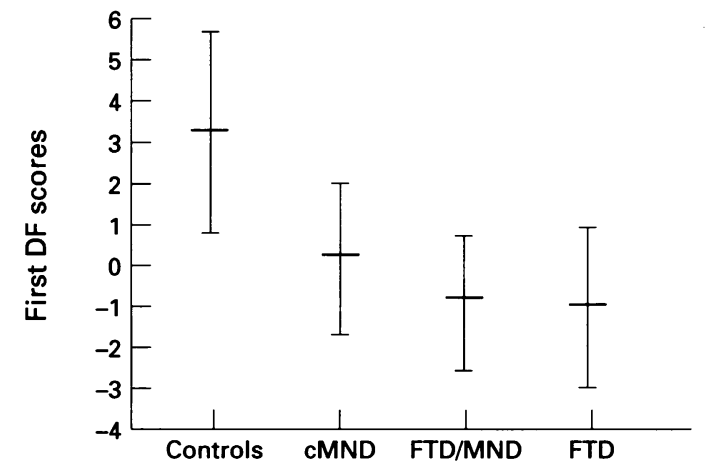

Table 3 and fig 2 show the mean $\mathrm{rCBF}_{\mathrm{i}}$ values for each region of interest in patient and control groups. In cMND, mean $\mathrm{rCBF}$ values were numerically lower than those in normal controls for all regions of interest. The differences in $\mathbf{r C B F}_{\mathrm{i}}$ values, however, between these two groups were most pronounced in frontal and anterior temporal cortices. In FTD/MND and FTD, reductions were substantially greater than in cMND, yet the topographical distribution of reductions compared with normal controls was very similar, most pronounced in frontal, anterior temporal, and high left sided parietal regions.
Table 3 Mean (SD) ${ }^{\prime C B F_{i}}$ data for study and reference groups

\begin{tabular}{|c|c|c|c|c|c|}
\hline \multirow[b]{2}{*}{ ROIs } & & \multirow[b]{2}{*}{ cMND } & \multicolumn{3}{|c|}{ Reference groups } \\
\hline & & & Controls & FTD/MND & FTD \\
\hline $\begin{array}{l}1 \\
2 \\
3 \\
4 \\
5 \\
6 \\
7 \\
8 \\
9 \\
10 \\
11 \\
12\end{array}$ & $\begin{array}{l}\text { Laof } \\
\text { Lmof } \\
\text { Lat } \\
\text { Lpt } \\
\text { Lpp } \\
\text { Loc/pp } \\
\text { Roc/pp } \\
\text { Rpp } \\
\text { Rpt } \\
\text { Rat } \\
\text { Rmof } \\
\text { Raof }\end{array}$ & $\begin{array}{l}75 \cdot 4(6 \cdot 0) \\
74 \cdot 1(6 \cdot 3)^{\star} \\
74 \cdot 4(7 \cdot 4)^{\star} \\
80 \cdot 9(5 \cdot 2) \\
81 \cdot 3(5 \cdot 2) \\
85 \cdot 2(6.5) \\
86.3(6 \cdot 1) \\
83 \cdot 2(5 \cdot 9) \\
83.4(5 \cdot 4) \\
79 \cdot 2(6 \cdot 0)^{\star} \\
78 \cdot 1(5 \cdot 2)^{\star} \\
75.9(5 \cdot 9)\end{array}$ & $\begin{array}{c}\text { Low } \\
78 \cdot 4(7 \cdot 6) \\
81 \cdot 1(7 \cdot 6) \\
80 \cdot 0(4 \cdot 0) \\
81 \cdot 4(3 \cdot 4) \\
83 \cdot 4(7 \cdot 4) \\
87 \cdot 0(7 \cdot 9) \\
88.5(7 \cdot 3) \\
85 \cdot 2(7 \cdot 5) \\
85 \cdot 9(4 \cdot 5) \\
83 \cdot 7(4 \cdot 3) \\
83 \cdot 3(6 \cdot 1) \\
78 \cdot 8(7 \cdot 4)\end{array}$ & $\begin{array}{l}65 \cdot 6(10 \cdot 3) \\
70 \cdot 0(5 \cdot 0) \\
73 \cdot 2(3 \cdot 1) \\
77 \cdot 4(5 \cdot 5) \\
74 \cdot 9(7 \cdot 1) \\
83 \cdot 6(9 \cdot 1) \\
87 \cdot 2(7 \cdot 6) \\
80 \cdot 0(3 \cdot 4) \\
80 \cdot 3(4 \cdot 8) \\
78 \cdot 3(6 \cdot 1) \\
70 \cdot 8(5 \cdot 6) \\
66 \cdot 5(10 \cdot 6)\end{array}$ & $\begin{array}{l}65 \cdot 8(12 \cdot 2) \\
68 \cdot 0(9 \cdot 5) \\
70 \cdot 5(9 \cdot 3) \\
76 \cdot 4(8 \cdot 9) \\
76 \cdot 5(9 \cdot 1) \\
83 \cdot 3(7 \cdot 9) \\
85 \cdot 8(7 \cdot 7) \\
80 \cdot 2(9 \cdot 2) \\
79 \cdot 8(8 \cdot 8) \\
75 \cdot 2(8 \cdot 9) \\
70 \cdot 0(9 \cdot 2) \\
67 \cdot 0(9 \cdot 5)\end{array}$ \\
\hline $\begin{array}{l}1 \\
2 \\
3 \\
4 \\
5 \\
6 \\
7 \\
8 \\
9 \\
10 \\
11 \\
12\end{array}$ & $\begin{array}{l}\text { Laf } \\
\text { Lmf } \\
\text { Lpf } \\
\text { Lap } \\
\text { Lpp } \\
\text { Loc/pp } \\
\text { Roc/pp } \\
\text { Rpp } \\
\text { Rap } \\
\text { Rpf } \\
\text { Rmf } \\
\text { Raf }\end{array}$ & $\begin{array}{l}78 \cdot 2(6 \cdot 8) \\
77 \cdot 4(5 \cdot 6) \\
76 \cdot 4(6 \cdot 4) \\
80 \cdot 6(6 \cdot 1) \\
80 \cdot 1(5 \cdot 7) \\
83 \cdot 8(7 \cdot 8) \\
85 \cdot 9(7 \cdot 5) \\
80 \cdot 0(5 \cdot 2) \\
81 \cdot 6(7 \cdot 0) \\
78 \cdot 6(6 \cdot 6) \\
78 \cdot 7(6 \cdot 3) \\
77 \cdot 8(6 \cdot 3)\end{array}$ & $\begin{array}{c}\text { Middle } \\
80 \cdot 5(6 \cdot 9) \\
79 \cdot 1(5 \cdot 3) \\
80 \cdot 0(5 \cdot 0) \\
82 \cdot 9(5 \cdot 6) \\
81 \cdot 2(6 \cdot 6) \\
84 \cdot 2(8 \cdot 0) \\
87 \cdot 9(6 \cdot 5) \\
81 \cdot 9(5 \cdot 7) \\
85 \cdot 0(4 \cdot 7) \\
82 \cdot 1(4 \cdot 7) \\
81 \cdot 1(6 \cdot 0) \\
79 \cdot 8(7 \cdot 8)\end{array}$ & $\begin{array}{l}65 \cdot 4(14 \cdot 2) \\
66 \cdot 9(9 \cdot 4) \\
71 \cdot 1(5 \cdot 3) \\
76 \cdot 6(5 \cdot 3) \\
75 \cdot 4(6 \cdot 1) \\
78 \cdot 8(8 \cdot 3) \\
80 \cdot 6(9 \cdot 4) \\
75 \cdot 4(5 \cdot 2) \\
77 \cdot 3(4 \cdot 5) \\
75 \cdot 5(6 \cdot 0) \\
70 \cdot 3(11 \cdot 8) \\
66 \cdot 6(14 \cdot 9)\end{array}$ & $\begin{array}{l}67 \cdot 8(13.4) \\
68 \cdot 3(11.5) \\
71 \cdot 3(8 \cdot 4) \\
76 \cdot 7(9 \cdot 5) \\
75 \cdot 0(8 \cdot 5) \\
80 \cdot 1(9 \cdot 1) \\
83 \cdot 2(10 \cdot 6) \\
77 \cdot 3(7 \cdot 7) \\
78 \cdot 1(10 \cdot 2) \\
75 \cdot 7(8 \cdot 6) \\
72 \cdot 4(9 \cdot 8) \\
68 \cdot 8(11 \cdot 7)\end{array}$ \\
\hline $\begin{array}{l}1 \\
2 \\
3 \\
4 \\
5 \\
6 \\
7 \\
8 \\
9 \\
10 \\
11 \\
12\end{array}$ & $\begin{array}{l}\text { Laf } \\
\text { Lmf } \\
\text { Lpf } \\
\text { Lap } \\
\text { Lpp } \\
\text { Lpp } \\
\text { Rpp } \\
\text { Rpp } \\
\text { Rap } \\
\text { Rpf } \\
\text { Rmf } \\
\text { Raf }\end{array}$ & $\begin{array}{l}79 \cdot 0(7 \cdot 3) \\
78 \cdot 6(6 \cdot 0) \\
77 \cdot 4(5 \cdot 6) \\
79 \cdot 6(5 \cdot 8) \\
80 \cdot 5(6 \cdot 2) \\
81 \cdot 7(6 \cdot 3) \\
84 \cdot 1(8 \cdot 1) \\
80 \cdot 0(6 \cdot 6) \\
80 \cdot 5(7 \cdot 1) \\
78 \cdot 4(7 \cdot 5) \\
79 \cdot 9(6 \cdot 4) \\
79 \cdot 2(6 \cdot 7)\end{array}$ & $\begin{array}{c}\text { High } \\
81 \cdot 6(7 \cdot 7) \\
80 \cdot 2(6 \cdot 1) \\
77 \cdot 7(4 \cdot 8) \\
80 \cdot 4(6 \cdot 4) \\
80 \cdot 7(5 \cdot 7) \\
83 \cdot 1(7 \cdot 8) \\
85 \cdot 1(5 \cdot 8) \\
80 \cdot 8(5 \cdot 2) \\
82 \cdot 7(5 \cdot 2) \\
80 \cdot 0(5 \cdot 8) \\
81 \cdot 4(6 \cdot 0) \\
81 \cdot 6(7 \cdot 6)\end{array}$ & $\begin{array}{l}67 \cdot 2(12 \cdot 3) \\
68 \cdot 2(10 \cdot 4) \\
71 \cdot 0(6 \cdot 7) \\
73.9(7 \cdot 4) \\
74 \cdot 4(6 \cdot 1) \\
76 \cdot 1(9 \cdot 1) \\
78 \cdot 0(9 \cdot 4) \\
76.9(7 \cdot 9) \\
76.0(4 \cdot 2) \\
73.3(5 \cdot 2) \\
68 \cdot 3(10 \cdot 5) \\
66.3(12 \cdot 2)\end{array}$ & $\begin{array}{l}69 \cdot 0(13 \cdot 3) \\
68 \cdot 7(10 \cdot 8) \\
70 \cdot 1(10 \cdot 1) \\
73 \cdot 2(9 \cdot 1) \\
73 \cdot 1(8 \cdot 8) \\
76 \cdot 5(10 \cdot 2) \\
78 \cdot 9(12 \cdot 2) \\
77 \cdot 0(9 \cdot 0) \\
76 \cdot 2(9 \cdot 9) \\
73 \cdot 7(9 \cdot 3) \\
72 \cdot 9(10 \cdot 3) \\
70 \cdot 3(10 \cdot 9)\end{array}$ \\
\hline
\end{tabular}

${ }^{\star}$ Significant $(\mathrm{P}<0.05)$ difference between $\mathrm{cMND}$ and control group mean $\mathrm{rCBF}_{\mathrm{i}}$ values $(t$ tes assuming unequal variance). $\mathbf{r C B F}_{\mathrm{i}}=$ indices of regional cerebral blood flow; ROIs = regions of interest; $\mathrm{L}=\mathrm{Left}$; $\mathrm{R}=\mathrm{Right}$; aof $=$ anterior orbitofrontal; mof $=$ middle orbitofrontal af = anterior frontal; $\mathrm{mf}=$ middle frontal; $\mathrm{pf}=$ posterior frontal; at = anterior temporal; $\mathrm{pt}=$ posterior temporal; $\mathrm{ap}=$ anterior parietal; $\mathrm{pp}=$ posterior parietal; oc = occipital cortex.
The first DF seemed to reflect an anteriorposterior asymmetry in $\mathrm{rCBF}_{\mathrm{i}}$ values (fig 3). Figure 4 summarises the group scores for the first DF: low scores indicate decreased frontal and anterior temporal $\mathrm{rCBF}_{\mathrm{i}}$ values compared with those in posterior temporal and parietal cortices. ANOVA showed significant differences between group scores for the first DF $(P<0.0001)$. Post hoc pair-wise comparisons showed that the first DF separated all patient groups from normal controls $(\mathrm{P}<$ $0.001)$ and $c M N D$ from FTD $(P=0.004)$ and FTD/MND $(P=0.04)$, but did not distinguish between FTD/MND and FTD $(P=$ $0.94)$. The mean group score for cMND was between that of normal controls and those of FTD/MND and FTD (fig 4). Although there were significant differences between group scores for the other DFs, they were difficult to interpret in a physiologically meaningful way. Furthermore, very different functions were produced if individual patients were removed from the analysis. It was therefore assumed that these DFs only reflect random sampling and not real effects.

\section{Discussion}

With respect to the neuropsychological evaluation, patients with cMND performed as well as normal controls for most tasks. Nevertheless, significant group differences were present between patients and normal controls for picture sequencing and token test scores. The picture sequencing task was similar to the picture arrangement subtest of the Wechsler adult intelligence scale (WAIS), ${ }^{36}$ which assesses the ability to plan, organise, and self monitor test performance, and has been considered sensitive to frontal lobe dysfunction. ${ }^{37}$ The present picture sequencing task was a much simplified version of the WAIS test, designed for children, which has been found to be sensitive to the frontal lobe deficit of patients with FTD/MND ${ }^{20}$ and FTD. ${ }^{22}$ Picture sequencing scores within the cMND group seemed to be widely distributed, suggesting a range of cognitive impairment. The token test is ostensibly a test of language comprehension, although sporadic errors might arise for extralinguistic reasons, such as poor attention, monitoring, and checking of responses. ${ }^{38}$ In the present study, results seemed to be biased by a few patients who made some perseverative errors. These patients were inattentive during testing, and were the same patients whose performance in the picture sequencing test was poor, suggesting that errors indeed occurred as a result of poor self regulation of performance rather than a primary linguistic disorder. Furthermore, no patient showed overt evidence of aphasia. Overall, the neuropsychological test results suggested preserved cognitive function in some patients with cMND with evidence of subtle frontal lobe dysfunction in others.

The neuropsychological finding of frontal lobe disorder in cMND is consistent with previous studies, which have shown abnormal 
scores in card sorting tests ${ }^{4} 5$ and impaired verbal fluency. ${ }^{67}$ In the present study, group differences between patients with $\mathrm{CMND}$ and normal controls for the scores of card sorting and verbal fluency tests did not reach significance. Nevertheless, there was a trend towards fewer categories in the card sorting test and reduced verbal fluency in patients with cMND than in normal controls. Some studies have shown apparently normal psychological test performance ${ }^{89}$ in cMND. One possible explanation for this apparent disparity lies in the fact that tests considered sensitive to frontal lobe dysfunction were not employed. Alternatively, if there is indeed a range of frontal lobe change in cMND, "normal" test performance may have reflected the patient sample in that particular study. A further study has revealed apparently "generalised" cognitive impairment ${ }^{3}$ in cMND. It has been argued that this apparently global, and therefore non-specific, pattern of cognitive impairment could be attributed to depressed mood. Alternatively, the interpretation of test results may have been incorrect, and overall performance may in fact have reflected inattention, poor planning, and self-monitoring due to frontal lobe dysfunction. ${ }^{38}$

In cMND, reductions in $\mathrm{rCBF}_{\mathrm{i}}$ values were most pronounced in the frontal and anterior temporal cortices. Furthermore, it was the degree of frontotemporal SPECT abnormality that separated the cMND group from normal controls. These findings are consistent both with the neuropsychological findings and the results of previous functional neuroimaging studies in CMND, which have shown cortical abnormality outside the motor cortices in prefrontal gyri ${ }^{18}$ and medial frontal regions. ${ }^{7}$ The fact that such neuroimaging findings have not been invariable 569161719 may have reflected differences in the sample of patients (the proportion of patients with $\mathrm{cMND}$ with cerebral involvement outside the motor cortices).

In both FTD/MND and FTD, severe frontotemporal SPECT abnormality reflected the pattern of psychological breakdown that was strongly indicative of frontal lobe dysfunction. ${ }^{20-22}$ These two conditions have previously been shown to manifest an identical profile of neuropsychological disorder (dementia), suggesting dysfunction of the anterior hemisphere. ${ }^{2022}$ It is not surprising, therefore, that canonical discriminant analysis of $\mathrm{rCBF}_{\mathrm{i}}$ data failed to distinguish reliably between FTD/MND and FTD. These results are consistent with the findings of previous functional neuroimaging studies, which have shown frontal and anterior temporal lobe abnormality in both FTD/MND ${ }^{18} 2023$ and FTD 3940 alone.

Patients with cMND seem to share similarities with patients with FTD/MND and FTD with respect to the pattern of cognitive impairment. In cMND, evidence of frontal lobe dysfunction has been elicited only by formal neuropsychological evaluation, whereas in FTD/MND and FTD, the frontal lobe disorder was profound and clinically evident, manifesting as dementia. This apparent clinical range of disorder has been reflected in the results of SPECT imaging, which showed a common pattern of cerebral abnormality in all three syndromes, and findings in cMND that seemed to represent an overlap between those of normal controls and FTD. It would seem that both neuropsychological and SPECT findings have implicated a common pattern of cerebral involvement in cMND, FTD/MND, and FTD, most pronounced in the last two conditions. This suggests that the three syndromes represent a clinical range of a pathological continuum; cMND results from initial brain stem and spinal cord involvement. The poor life expectancy associated with cMND ultimately limits disease spread into the frontal lobes and consequently, patients usually manifest either no or very mild frontal lobe impairment, and only rarely go on to develop profound neuropsychological dysfunction (FTD/MND). ${ }^{21}$ By contrast, initial and extensive frontal lobe involvement presents as FTD. In the event of disease spread to the brain stem, patients go on to develop FTD/MND, thereby curtailing the further progression of frontal lobe pathology. This hypothesis is supported by pathological studies that have shown frontotemporal atrophy in FTD/MND less severe than that encountered in FTD alone. ${ }^{24}$ Nosological relation between these apparently overlapping conditions, however, cannot be confirmed in the absence of defined pathological and molecular markers. ${ }^{24}$

An association between cognitive impairment and bulbar involvement in MND has been suggested, ${ }^{4}$ but others have failed to confirm a link. ${ }^{7}$ In the present study, only $21 \%$ of patients with cMND (selected on the basis of having no overt cognitive disorder), presented with bulbar symptoms. By contrast, $75 \%$ of patients with FTD/MND (in whom profound cognitive disorder was the presenting feature), manifested initial bulbar problems. These findings support a relation between psychological breakdown and bulbar involvement in MND. Within the cMND group, however, there were no statistically significant correlations between the pattern of clinical onset (bulbar $v$ limb) and the scores of cognitive tests. Nevertheless, the number of patients with initial bulbar involvement was small, so that a link cannot be excluded.

In conclusion, neuropsychological and SPECT findings in cMND, FTD/MND, and FTD show a common pattern of cerebral involvement, most pronounced in the last two conditions. These findings point to an important link between cMND and FTD. It is suggested that FTD/MND should be considered a clinical variant of $M N D$ and that the syndromes of cMND, FTD/MND, and FTD represent a clinical range of a common pathology.

1 Leigh PN, Ray-Chaudhuri K. Motor neuron disease. F Neurol Neurosurg Psychiatry 1994;57:886-96.

2 Hudson AJ, Amyotrophic lateral sclerosis and its association with dementia, parkinsonism and other neurological disorders: a review. Brain 1981;104:217-47. 
3 Gallassi R, Montagna P, Ciardulli C, Lorusso S, Mussuto $\mathrm{V}$, Stracciari A Cognitive impairment in motor neurone disease. Acta Neurol Scand 1985;71:480-4.

4 David AS, Gillham RA. Neuropsychological study of motor neuron disease. Psychosomatics 1986;27:441-5.

5 Langen KJ, Ludolph AC, Herzog H, et al. Glucose metabolism in amyotrophic lateral sclerosis: relation to clinical and neuropsychological status [abstract]. $¥$ Cereb Blood Flow Metab 1989;9(suppl 1):S24.

6 Ludolph AC, Langen KJ, Regard M, et al. Frontal lobe function in amyotrophic lateral sclerosis: a neuropsychologic and positron emission tomography study. Acta Neurol Scand 1992;85:81-9.

7 Kew JJM, Goldstein LH, Leigh PN, et al. The relationship between cognitive function and cerebral activation in amyotrophic lateral sclerosis-a psychological and positron emission study. Brain 1993;116:1399-423.

8 Poloni M, Capitani E, Mazzini L, Ceroni M Neuropsychological measures in amyotrophic lateral sclerosis and their relationship with CT scan-assessed cerebral atrophy. Acta Neurol Scand 1986;74:257-60.

9 Abe K, Fujimura H, Toyooka K, et al. Single-photon emission computed tomographic investigation of patients with sion computed tomographic investigation of patients
motor neuron disease. Neurology 1993;43: 1569-73.

10 Goodin DS, Rowley HA, Olney RK. Magnetic resonance imaging in amyotrophic lateral sclerosis. Ann Neurol $1988 ; 23: 418-20$

11 Sales Luis ML, Hormigo A, Mauricio C, Alves MM, Serrao R. Magnetic resonance imaging in motor neurone disease. F Neurol 1990;237:471-4.

12 Ishikawa K, Nagura H, Yokota T, Yamanouchi H. Signal loss in the motor cortex on magnetic resonance images in amyotrophic lateral sclerosis. Ann Neurol 1993;33: 218-22.

13 Fazakas F, Alavi A, Chawluk JB, et al. Comparison of CT, $\mathrm{MR}$, and PET in Alzheimer's disease and normal aging. f Nucl Med 1989;30:1607-15.

14 Eagger S, Syed GMS, Burns A, Barrett J, Levy R. Morphologic (CT) and functional (rCBF-SPECT) correlates in Alzheimer's disease. Nucl Med Comm 1992; 13: $644-7$.

15 Kwiecinski H, Krolicki L, Domzal-Stryga A. Magnetic resonance imaging and single photon emission computerised tomography of patients with amyotrophic latera sclerosis [abstract]. $\mathcal{f}$ Neurol 1994;241(suppl 1):S17.

16 Dalakas MC, Hatazawa J, Brooks RA, Di Chiro G. Lowered cerebral glucose utilisation in amyotrophic lateral sclerosis. Ann Neurol 1987;22:580-6.

17 Hatazawa J, Brooks RA, Dalakas MC, Mansi L, Di Chiro G. Cortical motor-sensory hypometabolism in amyotrophic lateral sclerosis : a PET study. $\mathcal{f}$ Comput Assist Tomogr 1988;12:630-6.

18 Waldemar G, Vorstrup S, Jensen TS, Johnson A, Boysen G. Focal reductions of cerebral blood flow in amyotrophic lateral sclerosis: a [99mTc]-d, $l$-HMPAO SPECT study. $¥$ Neurol Sciences 1992;107:19-28.

19 Hoffman JM, Mazziotta JC, Hawk TC, Sumida R, Phelps ME. Normal cerebral glucose utilisation in amyPhelps ME. Normal cerebral glucose utilisation in amyotrophic later

20 Neary D, Snowden JS, Mann DMA, Northen B, Goulding
PJ, Macdermott N. Frontal lobe dementia and motor neurone disease. 7 Neurol Neurosurg Psychiatry 1990;53 23-32.

21 Mitsuyama Y. Presenile dementia with motor neurone disease. Dementia 1993;4:137-42.

22 Neary D, Snowden JS, Northen B, Goulding P. Dementia of frontal lobe type. $\mathcal{F}$ Neurol Neurosurg Psychiatry 1988; 51:353-61.

23 Ohnishi T, Hoshi H, Jinnouchi S, Nagamachi S, Watanabe K, Mitsuyama Y. The utility of cerebral blood flow imaging in patients with the unique syndrome of progressive dementia with motor neuron disease. $\mathrm{F} \mathrm{Nucl}$ Med 1990;31:688-91.

24 Mann DMA, South PW. The topographic distribution of brain atrophy in frontal lobe dementia. Acta Neuropathol 1993;85:334 40 .

25 Brun A, Englund B, Gustafson L, et al. Clinical and neuropathological criteria for frontotemporal dementia. 7 Neurol Neurosurg Psychiatry 1994;57:416-8.

26 Swash M, Leigh PN. Criteria for the diagnosis of familia amyotrophic lateral sclerosis. Neuromusc Disord 1992;2: $7-9$.

27 Kaplan E, Goodglass H, Weintraub S. Boston naming test. Pennsylvania: Lea and Febiger, 1983

28 De Renzi E, Faglioni P. Normative data and screening power of a shortened version of the token test. Cortex 1978;14:41-9.

29 Warrington EK, James M. The visual object and space perception battery. Bury St Edmonds: Suffolk: Thames Valley Test Company, 1991.

30 Warrington EK. Recognition memory test. Windsor, Berkshire: NFER-Nelson, 1984.

31 Nelson HE. A modified card sorting test sensitive to frontal lobe defects. Cortex 1976;12:313-24.

32 Learning development aids. Wisbech, England: Balding and Mansell Ltd, 1975

33 Spreen O, Benton AL. Neurosensory centre comprehensive examination for aphasia (NCCEA). Victoria: University of Victoria Neuropsychology Laboratory, 1977.

34 Nelson HE. National adult reading test manual. Windsor, Berkshire: NFER-Nelson, 1982.

35 Talbot PR, Lloyd JJ, Snowden JS, Neary D, Testa HJ. The choice of reference region in the quantification of SPECT in primary degenerative dementia. Eur $₹$ Nucl Med 1994;21:503-8.

36 Wechsler D. WAIS-R manual. Cleveland, $\mathrm{OH}$ : The Psychological Corporation, 1981.

37 McFie J, Thompson JA. Picture arrangement: a measure of frontal lobe function. $\mathrm{Br} \mathcal{F}$ Psychiatry 1972;121: 547-52.

38 Snowden JS. Contribution to the differential diagnosis of dementias. 1: Neuropsychology. Reviews in Clinical Gerontology 1994;4:227-34.

39 Miller BL, Cummings $\mathrm{J}$, A Villanueva-Meyer J, et al. Frontal lobe degeneration: clinical, neuropsychological, and SPECT characteristics. Neurology 1991;41: and SPEC

40 Starkstein SE, Migliorelli R, Teson A, et al. Specificity of changes in cerebral blood flow in patients with frontal lobe dementia. $\mathcal{F}$ Neurol Neurosurg Psychiatry 1994;57: 790-6.

\section{Rauvolfia sevenetii (moonshine plant)}

The genus Rauvolfia was named after the 16th century German physician and explorer Dr Leonhard Rauwoff. It grows in most tropical forests of the Pacific, South America, Asia, and Africa and there are more than 100 species.

The plant - called chandrika or "moonshine plant" in Sanskrit - has long been valued in India as a sedative and hypnotic in the treatment of insanity, or "moon disease". Its active ingredient reserpine, isolated from the root of the rauvolfia in 1952, revolutionised the treatment of mental illness and hypertension. Holy men in India, including Mahatma Gandhi, have reportedly chewed the root of the rauvolfia to help achieve a state of philosophic detachment while meditating. It is shown on a medicinal plant set of stamps issued by New Caledonia in 1988 (Stanley Gibbons 831, Scott 579).

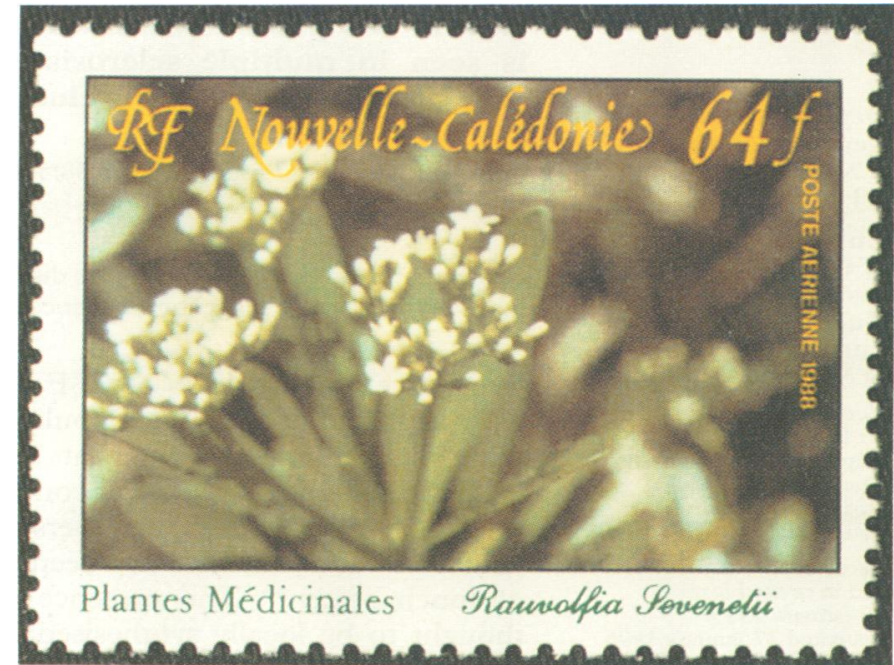

